
OF UNCERTAINTY AMONG GP TRAINEES

doi:10.1136/archdischild-2012-302724.1770

${ }^{1} \mathrm{~A}$ Loftus, 'L Keaveney, ${ }^{2} \mathrm{M}$ O'Neill. 'Western Training Programme in General Practice, Galway; ' ${ }^{2}$ epartment of Paediatrics, Mayo General Hospital, Castlebar, Ireland

Background and Aims Uncertainty is at the heart of clinical practice. The learning curve leading from apprentice to expert brings us into contact with uncertainty on a daily basis yet there is relatively little emphasis on it in medical training.

This project aimed to explore GP trainees' experience of uncertainty, its impact, and the skills required to counter it.

Methods An eight question survey was distributed to trainees on the Western Training Programme in General Practice exploring their decisiveness, their experience of uncertainty, and the resources they employed to deal with it. Results were analysed with Excel.

Results 45 questionnaires were returned (78\% response rate).

In terms of combating uncertainty, experience and knowledge of "red flags" ranked highest. Clinical knowledge and experience had the biggest impact on decision making, with fear of making a mistake more pronounced among trainees reporting higher degrees of uncertainty $(94 \%$ said it inflluenced their decisions compared to $58 \%$ of the occasionally uncertain). Patients' anxieties and expectations impacted to a lesser extent (74\%).

Conclusion How often trainees experience uncertainty may lessen with advancing clinical knowledge and experience. Support from senior colleagues is important, as is fear of making mistakes. Building personal resilience (emotional support, good lifestyle), and developing self-awareness didn't rank as highly in terms of what trainees found helpful in dealing with uncertainty; perhaps a reflection of a lack of emphasis on these in general in medical training and something that could be explored as a basis for student education in coping with uncertainty.

\section{USE OF OXIMETER IN CLINICAL ASSESSMENT OF INFANTS AT BIRTH IN LOW RISK DELIVERIES AFTER HOME BIRTH IN THE NETHERLANDS}

doi:10.1136/archdischild-2012-302724.1771

${ }^{1} \mathrm{M}$ Smit, ${ }^{2} \mathrm{~A}$ te Pas, ${ }^{3} \mathrm{~J}$ Dawson, ${ }^{2} \mathrm{~A}$ Ganzeboom. ${ }^{1}$ Obstetrics \& Gynecology; ${ }^{2}$ Neonatology, Leiden University Medical Center, Leiden, The Netherlands; ${ }^{3}$ Neonatology Research, The Royal Women's Hospital, Melbourne, VIC, Australia

Background Objective assessment of infant's condition at birth by oximeter is now recommended in resuscitation guidelines. However, midwives supervising home birth in primary care still use color and count heart rate for evaluation.

Aim To evaluate the additional value of an oximeter when assessing term infants after birth in a home birth setting.

Methods During ten months 27 midwives supervising (home) births used a Masimo oximeter directly after birth for ten consecutive minutes. Data were obtained concerning outcomes, interventions, usefulness, applicability and decision-making.

Results During the study period the oximeter was used in 153 uncomplicated births in primary care. Only one infant received supplemental oxygen and one infant received bag and mask, which was the only hospital referral after birth.

The majority of midwives (88\%) found the oximeter easy to use, but in their clinical judgment was not influenced by the use of the oximeter (in $97 \%$ of births). In 5 cases (3\%), the midwife felt uncertain about the infant's condition and the oximeter gave reassurance in all cases and it was decided not to refer.

Forty percent of midwives indicated to use the monitor again if they had one available and in case of suboptimal neonatal condition, all midwives would use it.
Conclusions It is feasible to use an oximeter during low-risk deliveries at home or in hospital, but was not considered an important contribution for evaluation in majority of the cases. However, midwives would prefer the availability of this device in case of suboptimal neonatal condition.

\section{ALKALINE PHOSPHATASE ACTIVITY IN HUMAN COLOSTRUMS AS A VALUABLE PREDICTIVE BIOMARKER FOR LACTATING MASTITIS IN NURSING MOTHERS}

doi:10.1136/archdischild-2012-302724.1772

${ }^{1} \mathrm{~L}$ Bjelakovic, ${ }^{2} \mathrm{G}$ Kocic, ${ }^{3 B}$ Bjelakovic, ${ }^{4} \mathrm{~N}$ Zivkovic, ${ }^{5} \mathrm{D}$ Stojanovic, ${ }^{2} \mathrm{D}$ Sokolovic. ${ }^{1}$ Department of Hygiene, Faculty of Sport and Physical Education, University of Nis; ${ }^{2}$ Institute of Biochemistry, Medical Faculty, University of Nis; ${ }^{3}$ Cardiology, Clinic of Pediatrics, Clinical Center; ${ }^{4}$ Institute of Pathology; ${ }^{5}$ nstitute of Hygiene, Medical Faculty, University of Nis, Nis, Serbia

Mastitis is defined as an inflammation of the mammary gland. It often presents with the disease already at an advanced stage when the treatment is less effective and the health consequences for nursing mothers and their newborn babies are more severe.

From the pediatric viewpoint it is extremely important to predict occurrence of lactating mastitis as early as possible in order to prevent vertical transmission of infections from mother to infant as well as to prevent stopping of newborn breast feeding.

Biochemical investigations have shown that indigenous milk enzyme such as alkaline phosphatase (ALP) which is detectable in the cuboidal (epithelial) mammary gland cells, plays a very important diagnostic role in clinical medicine, since its activity varies in different tissues and serves as a specific indicator of diseased states.

The purpose of this study was to evaluate ALP activity in human colostrum as a possible early predictive biomarker for lactating mastitis in nursing mothers.

During a period from May to July 2010, a total of 60 healthy nursing mothers were prospectively followed from day 1 postpartum to the end of their lactation.

There was a significant difference in colostrum ALP activity $(p<0.001)$ from the breast with mastitis when compared with both the contralateral asymptomatic breast and "healthy" breasts.

In our opinion, determining ALP activity in colostrums could be a valuable biochemical marker for an early prediction of mastitis in nursing mothers.

\section{CHEST DRAIN INSERTION AND TRAINING OF NEONATAL DOCTORS: USE OF AN ANIMAL MODEL}

doi:10.1136/archdischild-2012-302724.1773

'S Garg, 'C Buckely, ${ }^{2} Z$ Sharp, 'S Byrne. 'Neonatal Medicine, South Tees Hospitals NHS Foundation Trust, Middlesbrough, UK; ${ }^{2}$ Cook Medical, Cook Europe Shared Service Centre, Limerick, Ireland

Background and Aims Neonatal pneumothorax is a potentially fatal condition if not managed promptly and effectively. The little training in chest drain insertion is highlighted by doctors regularly. This is compounded by various factors including decreased incidence of pneumothorax and decreased working hours.

The animal models have been used for such training. We started and tested such training model in our unit to improve the skills and confidence of junior doctors in chest drain insertion.

Methods The workshop included presentation (theoretical), videos of procedure and then the hands on experience on dead rabbits. The rabbits were prepared by the local butchers and were easily available. The training was delivered ( 2 hour) as part of regular departmental teaching programme and was conducted in the first few weeks of start of job. A three point likert scale was used to record the feedback. 
Results 25 colleagues were trained including 17 junior doctors, 3 consultants and 3 advanced neonatal nurse practitioners (23 feedbacks received).

All of the them fedback that the session fully met their professional needs.

Everybody (23) felt that the integration of theory and practical in this way was excellent.

3 participants did not have any opinion about using the animal model. One person did not like the idea of animal model (religious reasons).

Conclusion A rabbit model for chest drain training was found to be extremely useful to majority of our trainees. This type of training should be arranged once every 6 months with the changing team of junior doctors.

\section{CAUSE OF RESPIRATORY DISTRESS IN NEONATAL INTENSIVE CARE UNIT: A RETROSPECTIVE EVALUATION}

doi:10.1136/archdischild-2012-302724.1774

${ }^{1} \mathrm{~A}$ Annagür, ${ }^{2} \mathrm{H}$ Altunhan, ${ }^{3} \mathrm{~S}$ Arıbaș, ${ }^{3} \mathrm{M}$ Konak, ${ }^{3} \mathrm{R}$ Örs. 'Department of Neonatology, Selcuk University, Selcuklu Medical Faculty, Konya; ${ }^{2}$ Department of Neonatology, Abant Izzet Baysal University, Medical Faculty, Bolu; ' ${ }^{3}$ Department of Neonatology, Konya University, Meram Medical Faculty, Konya, Turkey

Purpose To determine the demographic characteristics of the newborns with respiratory difficulties, frequency of neonatal disease, analyze of the prognostic factors and effectiveness of treatment who were hospitalized in NICU of our hospital between 2008 and 2009.

Methods In this study, file records of the newborns who were hospitalized in NICU of Selcuk University, Meram Medical School were analyzed retrospectively.

Results Of the 771 newborns, 225 who admitted due to respiratory distress in 2008 and of the 692 newborns, 282 who admitted due to respiratory distress in 2009. Mean birth weight was $1954 \pm 972 \mathrm{gr}$ in 2008 , and $2140 \pm 1009 \mathrm{gr}$ in 2009. Mean pregnancy weeks were $32.4 \pm 5.0$ in 2008 and $33.4 \pm 4.9$ in 2009. Diagnosis of patients were sepsis $(77.8 \%)$, respiratory distress syndrome (RDS) (40.4\%), pneumothorax (20.9\%), patent ductus arteriosus (PDA) $(12.4 \%)$, meconium aspiration syndrome (MAS) (6.2\%), intraventricular hemorrhage (IVH) (5.3\%), pneumonia (3.6\%), retinopathy of prematurely (ROP) (3.1\%), bronchopulmonary dysplasia (BPD) $(2.7 \%)$ and transient tachypne of newborn (TTN) $(2.2 \%)$ in 2008 . In 2009 , percentage of the diagnosis was $69.5 \%$ sepsis, $33.3 \%$ RDS, $17.0 \%$ PDA, $16.0 \%$ pneumothorax, $10.3 \%$ pneumonia, $8.2 \%$ IVH, $6 \%$ TTN, $5.3 \%$ BPD, $3.2 \%$ MAS and $3.2 \%$ ROP. $33.7 \%$ of the patients were died in 2009 and $43.6 \%$ of them in 2008.

Conclusion The newborns with respiratory distress who admitted to the hospital must be evaluated according to the pregnancy week, way of birth and accompanying problems during first examination and convenient transportation of the ones who need to be cared in advanced center where an intensive care support can be applied to decrease mortality and morbidity of newborns distress.

\section{THE EVALUATION OF LUNG FUNCTION MEASURED BY IMPULSE OSCILLOMETRY METHOD IN VERY LOW BIRTH WEIGHT BORN CHILDREN AT PRESCHOOL AGE}

doi:10.1136/archdischild-2012-302724.1775

'M Oruç, 'A Günlemez, ${ }^{2} Z S$ Uyan, 'AS Gökalp, 'N Kavas, ' $\mathrm{G}$ Türker, 'AE Arısoy. 'Neonatology; ${ }^{2}$ Pediatric Pulmonology, Kocaeli University, Kocaeli, Turkey

Chronic lung disease is one of the most important complications of prematurity and results in short and long-term morbidity. Survival of more prematurely born babies leads to an increase in the incidence of bronchopulmonary dysplasia (BPD).
The Aim of this study is to evaluate the lung function of babies who were born under birth weight of 1500 grams using impulse oscillometry in preschool age.

Eighty-six children who were 3-6 years old and followed in our neonatology clinic (born under birth weight of 1500 grams) were enrolled in the study as the patient group and 40 term-born healthy children as the control group. The demographic data of the patients, duration of mechanical ventilation and oxygen therapy and presence of BPD were recorded. After routine physical examination, lung functions of the patients were measured by impulse oscillometry. The data were evaluated by SPSS 16 program.

Forty-nine $(57 \%)$ of 86 patients were non-BPD, 20 were mild $\mathrm{BPD}, 14$ were moderate $\mathrm{BPD}$ and 3 were severe $\mathrm{BPD}$.

Weight and height of pramature and control groups were similar. There was a statistically significant difference between the two groups in terms of resistance (R5, R10, R20), reactance (X5, X10, $\mathrm{X} 20$ ) and resonant frequency (fres). The airway resistance was significantly higher and reactance was significantly lower in the premature group. However, there was no difference between BPD and non-BPD groups.

In conclusion; although premature babies can catch-up their peers at 3-4 years old in terms of their body percentiles, their lungs still reflect the traces of prematurity.

\section{RESPONSE THRESHOLDS TO PULSE OXIMETRY ALARMS IN THE NICU - AN OBSERVATIONAL STUDY}

doi:10.1136/archdischild-2012-302724.1776

1,2K Tan, ${ }^{2} \mathrm{~A}$ Clarke, ${ }^{2} \mathrm{P}$ Berger, ${ }^{2} \mathrm{E}$ Skuza, ${ }^{1,2} \mathrm{~A}$ Ramsden. 'Monash Newborn, Monash Medical Centre; ${ }^{2}$ Ritchie Centre, Monash Institute for Medical Research, Monash University, Melbourne, VIC, Australia

Background and Aims Manual control of oxygen delivery to premature infants is conducted mainly by NICU nurses. This involves $\mathrm{F}_{1} \mathrm{O}_{2}$ adjustments in order to keep the $\mathrm{S}_{\mathrm{p}} \mathrm{O}_{2}$ within a specific target range (88-92\%). Pulse oximeters have alarms set to alert the nurses when $\mathrm{S}_{\mathrm{p}} \mathrm{O}_{2}$ values are outside the range (85-95\%). Our aims were to study $\mathrm{F}_{\mathrm{I}} \mathrm{O}_{2}$ alteration in terms of magnitude and time outside target immediately before the $\mathrm{F}_{\mathrm{I}} \mathrm{O}_{2}$ change.

Methods Infants receiving CPAP or ventilation on the Babylog 8000 ventilator (Dec 2010- Apr 2012) were studied. Signals were acquired from oximeters and ventilator using the PowerLab data acquisition system. The 9-minute epoch prior to each $\mathrm{F}_{\mathrm{I}} \mathrm{O}_{2}$ change: $\mathrm{F}_{\mathrm{I}} \mathrm{O}_{2}$ increase $(\Delta \mathrm{POS})$ and $\mathrm{F}_{\mathrm{I}} \mathrm{O}_{2}$ decrease $(\Delta \mathrm{NEG})$ were studied.

Results Recordings were obtained from 7 (5 male) infants with mean $( \pm$ SD) gestation of $26.9( \pm 1.9)$ weeks and birthweight 767 $( \pm 200)$ g. $253 \mathrm{~F}_{\mathrm{I}} \mathrm{O}_{2}$ adjustments were recorded (130 $\Delta \mathrm{POS}$ and 123 $\triangle \mathrm{NEG}$ ) from 105 hours of total recording time. Mean (range) magnitude of $\triangle \mathrm{POS}$ and $\triangle \mathrm{NEG}$ was $4.6 \%(0.5-19.5)$ and $4.5 \%(0.5-57.0)$ respectively. Proportion time spent with low alarm in the 9 minutes before $\triangle \mathrm{POS}$ was $50.8 \%$, with $28.4 \%( \pm 20.2)$ of time in $80-85 \%$, $15.8 \%( \pm 16.7)$ in $70-80 \%$ band and $6.6 \%( \pm 11.3)$ less than $70 \%$ saturation. $22.5 \%$ of time was spent with high alarm (before $\Delta \mathrm{NEG)}$ with $4.3 \%( \pm 8.7)$ time $\mathrm{S}_{\mathrm{p}} \mathrm{O}_{2}$ exceeding $98 \%$ and $7.7 \%( \pm 11.4)$ in 96-98\% band.

Conclusion Nurses were more likely to tolerate low oxygen saturations than high saturations in preterm infants. Mild desaturation episodes (between 80-85\%) were often managed conservatively. 